\title{
Teacher training in the use of a three-dimensional immersive virtual world: Building understanding through first-hand experiences
}

\author{
Kevin $\mathrm{Oh}^{1}$ and Natalie Nussli ${ }^{2}$
}

Abstract: This study offers recommendations and a model for other teacher educators who are interested in training teachers in the use of three-dimensional (3D) immersive virtual worlds (IVWs) for their own teaching. Twelve special education teachers collaboratively explored the usability of Second Life (SL) for special education by completing a full inquiry cycle to develop the ability to make informed decisions about the affordances and challenges of virtual world teaching and to help identify effective components for virtual worlds teacher training. Ten educational SL islands were explored critically. Mixed-methods data analysis and triangulation were based on the analysis and synthesis of a preliminary survey, a mid-reflection after several virtual explorations, the collaborative analysis of an existing SL lesson plan, the collaborative development of a SL lesson plan, a post-reflection, and a post-survey. Several key benefits of $3 D I V W s$ for special education students emerged from the qualitative analyses, namely social skills practice, collaborative learning towards a joint goal with a competitive element, and increased motivation to participate, especially for topics that would otherwise be perceived as boring. The qualitative data informed the development of guidelines for virtual worlds teacher training and the elements of an ideal SL island designed for special education. The change of attitude towards the usability of virtual worlds in education as a result of the workshop was not statistically significant.

Keywords: three-dimensional immersive virtual worlds; Second Life; special education; teacher training

\section{Introduction}

In recent years, educational researchers and teacher educators have shown great interest in the use of three-dimensional (3D) immersive virtual worlds (IVWs) in instructional design and assessment (e.g., Chapman \& Stone, 2010; Johannesen, 2013; Mayrath, Traphagan, Heikes, \& Trivedi, 2011), inquiry-based learning (e.g., Barab, Sadler, Heiselt, Hickey, \& Zuiker, 2010; Good, Howland, \& Thackray, 2008; Nelson \& Ketelhut, 2007), inquiry-based learning in special education (e.g., Harlow \& Nilsen, 2011), and language development (e.g., Balcikanli, 2012; Blasing, 2010; Grant \& Clerehan, 2011; Ishizuka \& Akama, 2012; Knutzen \& Kennedy, 2012; Mroz, 2012; Wang, Calandra, Hibbard, \& Lefaiver, 2012; Wehner, Gump, \& Downey, 2013). Among these 3D IVWs, Second Life (SL) has emerged as one of the most popular platforms. Although the use of SL islands in the areas of learning has greatly varied among learning communities, the lack of research in preparing teachers to use 3D IVWs for effective teaching has been widely reported (e.g., Connor \& Sakshaug, 2009; Guasch, Alvarez, \& Espasa, 2010;

\footnotetext{
${ }^{1}$ Assistant Professor, Learning and Instruction Department, University of San Francisco, koh2@usfca.edu

${ }^{2}$ Doctoral student, Learning and Instruction Department, University of San Francisco, nnussli@gmail.com
} 
Pérez-García, 2009; Storey \& Wolf, 2010). Many universities have used SL to provide a platform for their students to discuss, share, and present materials to each other. But despite its potential to enhance education there are still only few empirical reports about the implementation of teacher training to incorporate this technology in teaching (Guzzetti \& Stokrocki, 2013; Nussli $\& \mathrm{Oh}$, in press). Virtual environments may also offer interesting opportunities for people with disabilities in terms of social experiences (Stendal, Balandin, \& Molka-Danielsen, 2011). Attending virtual concerts and experiencing other cultures and countries through virtual traveling are some of the benefits of the elimination of physical barriers. Other affordances, which may increase the quality of life, include the elimination of barriers to social participation, such as sharing a sense of a community (Stendal et al., 2011). The overarching goal of this study was to increase special education teachers' awareness of the potential of $3 \mathrm{D}$ technologies for special education purposes. The study was guided by the overall question how to train special education teachers in the use of SL so they can transfer these skills to their own teaching.

\section{Background}

Schroeder's (2008) definition of virtual reality is "a computer-generated display that allows or compels the user (or users) to have a sense of being present in an environment other than the one they are actually in, and to interact with that environment" (p. 1). Educational platforms can be found in the areas of astronomy, medicine, music, literature, biology, history, mathematics, forensic science, ecology, and tourism, to name a few. Learners can gain a greater understanding of abstract concepts; they can improve their understanding by manipulating and scaling virtual objects or environments; and they can visit places that distance, time, or safety concerns would normally prohibit (Jackson \& Fagan, 2000). This means that learners can immerse themselves in situations that would be impossible in real life (e.g., exploring the surface of the moon or a strand of a DNA molecule), take advantage of 3D data visualizations (such as the Pythagorean theorem), see hidden unseen phenomena (forces directed on an object), and enjoy easy access to museum artifacts (Barab, Hay, Barnett, \& Keating, 2000). Nanotechnology Island, for instance, offers an exploration of the minute details of the most miniature, microscopic technology that humans have developed. Another example of an educational space in SL is Etopia Island, which is a virtual world that emulates a socially and environmentally sustainable world. Sploland (Rothfarb \& Doherty, 2007), which houses the Splo Museum with more than 100 scientific exhibits, exemplifies experiential learning in virtual worlds.

\section{Virtual Environments for Special Education Purposes}

One of the purposes of this study was to have special education teachers reflect on the potential of 3D IVWs for special education students. In their theoretical review of educational uses of SL, Salt, Atkins, and Blackall (2008) identified what it could be used for, namely: (a) enhanced reality spaces for learning, (b) metaphorical representations of abstract concepts, (c) construction of own meaning and learning through interaction with SL objects, (d) simulations of real world activities, (e) practicing life skills, and (f) foreign language acquisition. Virtual environments also allow for a simulation of situations, which makes these environments particularly interesting for special education. They have been shown to offer potential affordances to develop social and communicative skills and provide educational intervention for individuals with social skills challenges, such as autism spectrum disorders (ASD). Mitchell, 
Parsons, and Leonard (2006), for instance, demonstrated how virtual environments could be used to teach social understanding and empathy to adolescents with autism. Training in a virtual café led to significant improvements in the participants' judgments and explanations about where to sit. In a study by Moore, Cheng, McGrath, and Powell (2005), individuals with autism demonstrated the ability to identify emotions of avatars. Another example of positive learning gains was illustrated in Kandalaft, Didehbani, Krawczyk, Allen, and Chapman (2013), whose participants showed significant increases in real-life functioning after a virtual reality intervention.

The key advantages of a virtual environment for people with social skills challenges include: (a) anonymous interactions and high levels of interactivity without requiring the complex language and social behavior that are typically necessary for face-to-face conversations (Fusar-Poli, Cortesi, Borgwardt, \& Politi, 2008); (b) a relatively safe space where social mistakes are less catastrophic than in a real environment (Strickland, 1997); (c) a space where a sense of collaboration, community, and cohesion can be developed, and where rules can be learned and tasks repeated (Fusar-Poli et al., 2008); and (d) a space that reduces the stress and sense of risk that can occur during direct interaction with another person (Smith, Swanson, Holverstott, \& Duncan, 2007). Virtual environments are considered a suitable platform for the simulation of social events, potentially allowing insight into others' minds. One such example is described in DeAngelis (2009). Patients enter a protected area in SL where their avatars practice communicating in realistic settings under the guidance of a therapist. The therapist only enters the scene when needed. After practicing social skills in a safe space with therapeutic aims, for example on Brigadoon, a private SL island designed for individuals with autism, individuals can venture out to public virtual spaces and interact with anyone (Gorini, Gaggioli, Vigna, \& Riva, 2008). Overall, looking across these studies suggests that virtual environments do have potential in special education, such as for the practice of social encounters (Newbutt \& Donegan, 2010).

\section{Inquiry-Based Learning}

The study was set in the context of inquiry-based learning to provide the participating special education teachers with the opportunity to experience inquiry-based learning first-hand. In the National Science Education Standards (NSES), the National Research Council (1996) defined inquiry as:

Inquiry is a multifaceted activity that involves making observations; posing questions; examining books and other sources of information to see what is already known in light of experimental evidence; using tools to gather, analyze, and interpret data; proposing answers, explanations, and predictions; and communicating the results. Inquiry requires identification of assumptions, use of critical and logical thinking, and consideration of alternative explanations. (p. 23)

Figure 1 shows the inquiry cycle that was adapted from Lin and Tallman (2006) for the purposes of this study. The cycle highlights students' responsibility for their own learning and on learners' taking action with the goal of being able to make informed decisions about the potential uses of 3D IVWs for education. 


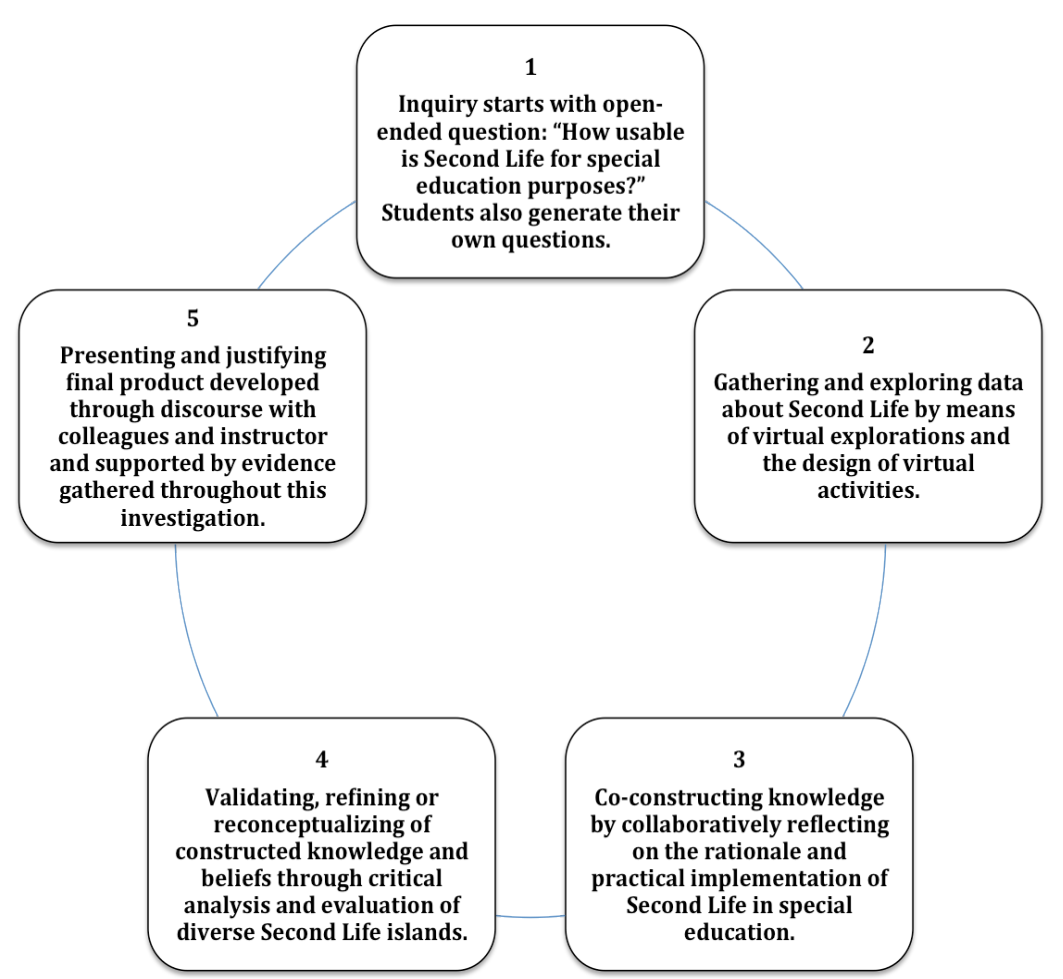

Figure 1. The inquiry cycle used for teacher training in this study (adapted from Lin \& Tallman, 2006).

\section{Purpose}

The purpose of this study was to increase participants' awareness of the potential of emerging 3D technologies for learning and instruction with a focus on special education. The study was guided by the question how to train special education teachers in the use of SL so they can transfer these skills to their own teaching. The inquiry included the following steps: (a) learning to navigate in SL, (b) reading research about the unique affordances of virtual learning environments, (c) experiencing SL first-hand by exploring a variety of islands, (d) discussing these islands' educational potential, and (e) analyzing a lesson plan. Special emphasis was put on the rationale and practical implementation of using 3D IVWs for education. In other words: Why and how could virtual worlds be used in education? Are there tasks that cannot be achieved equally well in different settings? Finally, the participating special education teachers were given the opportunity to create their own lesson plans in SL and get their colleagues' and the professor's feedback with the purpose of experiencing first-hand how their pedagogical methods need to be adjusted to a different environment. In summary, the objective of this process was for special education teachers to explore one example of immersive virtual worlds, namely SL, and to come to a conclusion based on their experiences about its usability for both general and special education students. The study was guided by the following research questions:

1. How can we best train special education teachers for the use of SL in their own teaching?

2. What are some of the affordances and challenges the special education teachers encountered in this SL workshop?

3. What guidelines can be established for special and general education teachers when incorporating virtual learning environments in their own teaching? 
4. What should an ideal 3D IVW platform look like to meet the needs of special education?

\section{Methodology}

An exploratory case study was used to measure the participants' attitude towards the use of virtual worlds in education before, during, and after a workshop.

\section{Participants}

Twelve (11 female, 1 male) special education teachers were enrolled in a graduate-level technology course specifically designed for special education teachers. The class met once a week for four hours during an entire semester. One of the projects in this class was for students to familiarize themselves with 3D IVWs and reflect on their experiences. All special education teachers reported having no experience using SL. They work in a wide variety of positions, including public and non-public K-12 schools as special day class teachers or as resource and inclusion specialist.

\section{Procedures and Instruments}

The participants' inquiry started with an open-ended question for investigation: "How usable is SL for general and special education purposes?" The special education teachers had to complete eleven steps during which they re-conceptualized their beliefs and refined their conclusions. The purpose of the inquiry approach was to provide the opportunity to build knowledge from first-hand collaborative experiences and reflection. Throughout the process, students were repeatedly confronted with the question of the meaningfulness of 3D IVWs for education. Appendix 1 shows an overview of all steps and how each step is framed by inquirybased learning. The time used for the entire project was approximately 15 hours of class time including five hours of homework. The last column explains how each step fits into inquirybased learning. Each step and instrument, including rationale, will be briefly described. The research methodology reflects that all special education teachers participating in this study were inexperienced users of 3D IVWs, similar to other studies revolving around virtual worlds teacher training (e.g., Annetta, Murray, Gull Laird, Bohr, \& Park, 2008; Dickey, 2011; O’Connor, 20092010; Storey \& Wolf, 2010). They were provided with clear guidance in the first few steps of the workshop. Once they were sufficiently familiar with both the technology and the rationale behind the workshop, that is, developing the ability to make informed decisions about the educational potential of 3D IVWs, less scaffolding was offered. The inquiry-based approach that was chosen to frame their learning supported this scaffolding process accordingly.

\section{Preliminary survey}

The initial version of the survey about teachers' perception of the usability of virtual worlds for education consisted of 49 items and was pilot-tested on 32 educators. The items were generated from the key dimensions that emerged from a review of the literature (Barbour \& Reeves, 2009; Fetscherin \& Lattemann, 2008; Verhagen, Feldberg, van den Hooff, Meents, \& Merikivi, 2011; Warburton, 2009), thereby providing construct-related evidence of validity. The 
survey was constructed using declarative statements on a five-point Likert scale (1=strongly disagree, 2=disagree, 3=don't know, 4=agree, 5=strongly agree). Negatively keyed items were reverse scored so that higher scores indicate more agreement, that is, higher perceived usability of $3 \mathrm{D}$ IVWs for education. Table 1 shows the preliminary survey questions, which were also included in the post-survey.

Table 1

Survey Questions

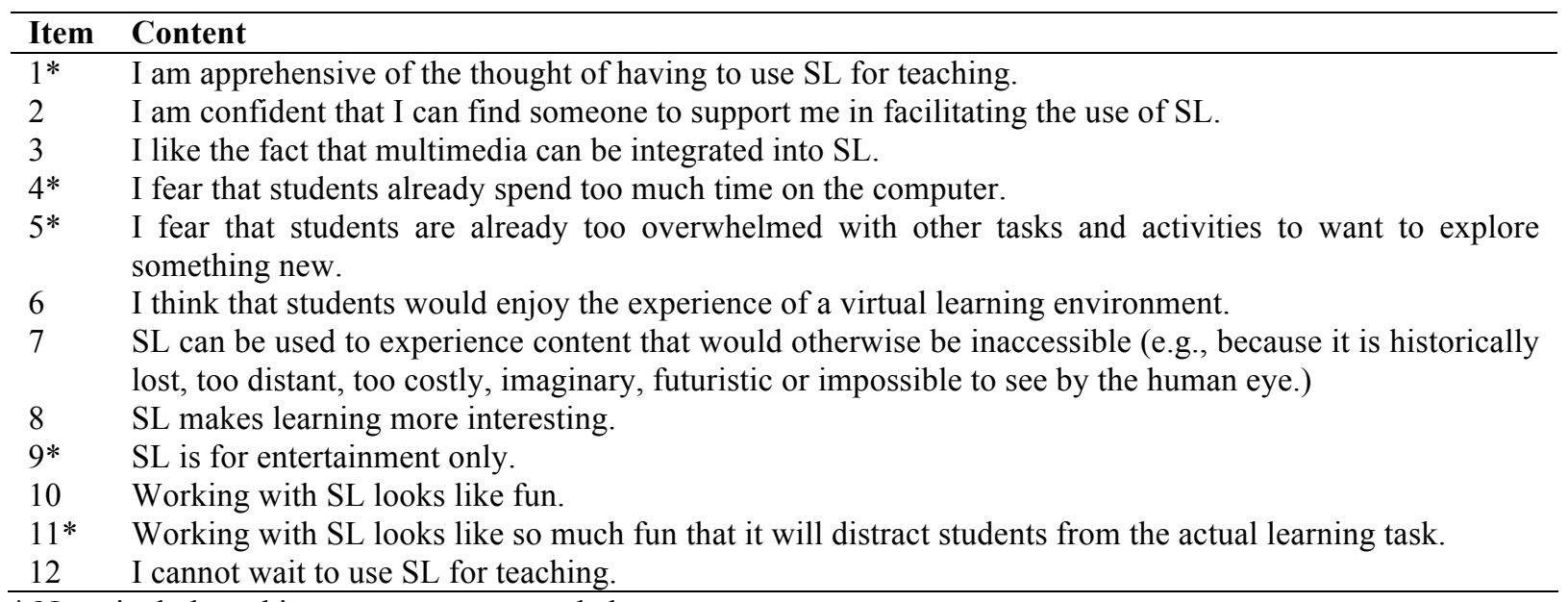

* Negatively keyed items were reverse coded.

\section{Preliminary activities (steps 1-4)}

In step 1, the participants' inquiry started with an open-ended question for investigation: "How usable is Second Life for general and special education purposes?" Students had to complete several steps to come to a conclusion. After watching a five-minute video on Youtube about the National Oceanographic and Atmospheric Association (NOAA) island in SL, participants completed a preliminary survey about their perceptions of the usability of SL for education. In step 2, all participants created their own SL account, downloaded Phoenix viewer, and learned basic navigation with the help of a highly pictorial SL manual created specifically for this class. Step 3 was a preliminary fieldtrip to five SL islands (Media Zoo, The Abyss Observatory, Virtual Hallucinations, Exploratorium, Genome Island) to ensure that students master the navigation skills required for the actual assignment. Figure 2 shows four of these islands.

Participants watched a 7-minute video in which the activities to be completed on each island were modeled by one of the researchers. Afterwards, they completed these preliminary tasks in a computer laboratory. One researcher was physically available for assistance on site while the second researcher was available for assistance in SL, connected through Skype for voice communication. For evidence of task completion, participants submitted screenshots to the instructor showing their avatar in each of the five SL islands. In step 4, participants read about five unique affordances of 3D IVWs in Dalgarno and Lee (2010), namely: experiential learning, spatial representation, motivation, transfer, and collaboration (Figure 3). 


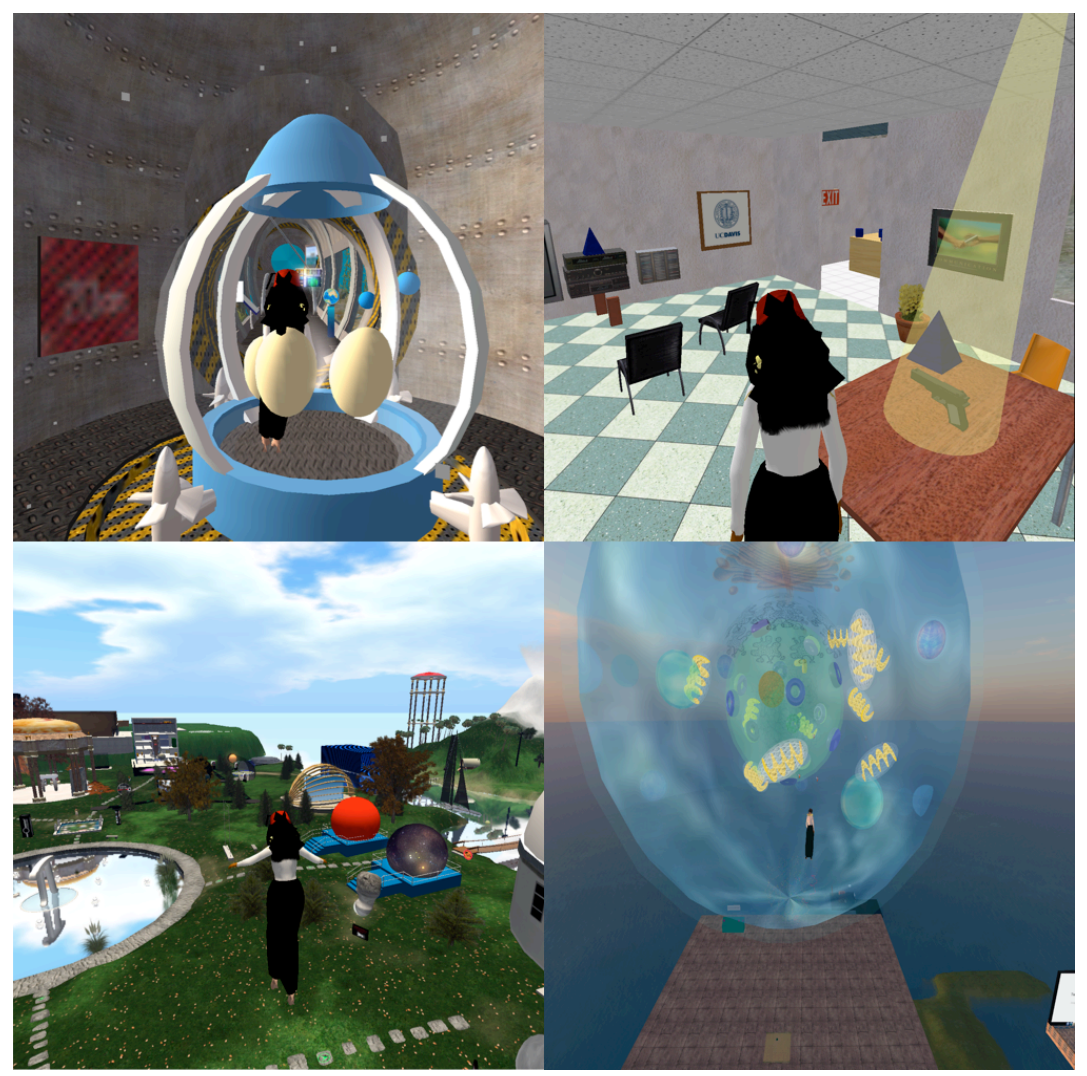

Figure 2. Preliminary fieldtrip (from upper left to lower right: Abyss Observatory, Virtual Hallucinations, Exploratorium, Genome Island).

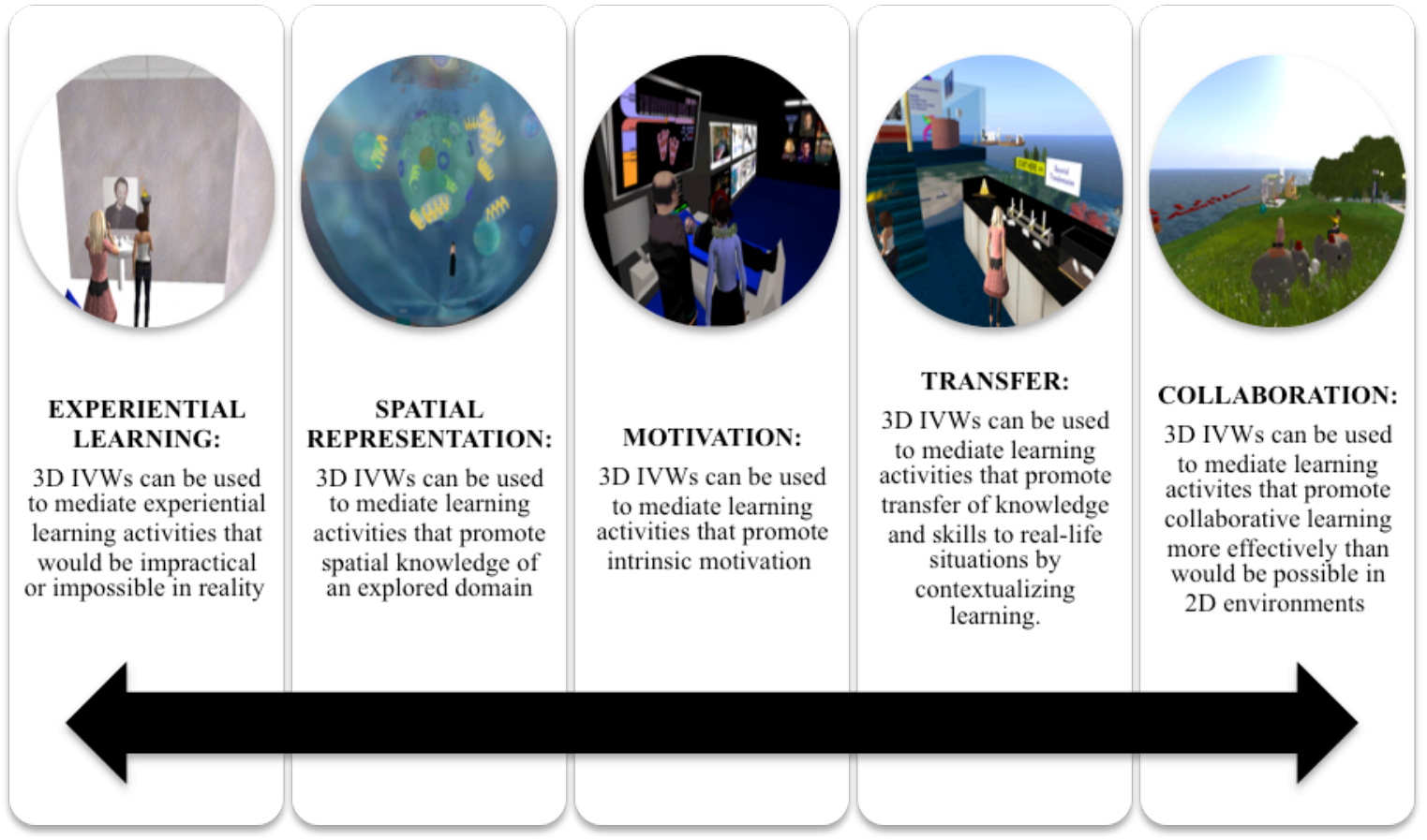

Figure 3. The five unique affordances of 3D IVWs (Dalgarno \& Lee, 2010). 
In step 5, participants explored SL collaboratively in groups of three. The purpose of this task was to brainstorm on potential activities and the rationale of using virtual worlds for education. Groups selected two out of five pre-selected islands to explore in depth (Figure 4).

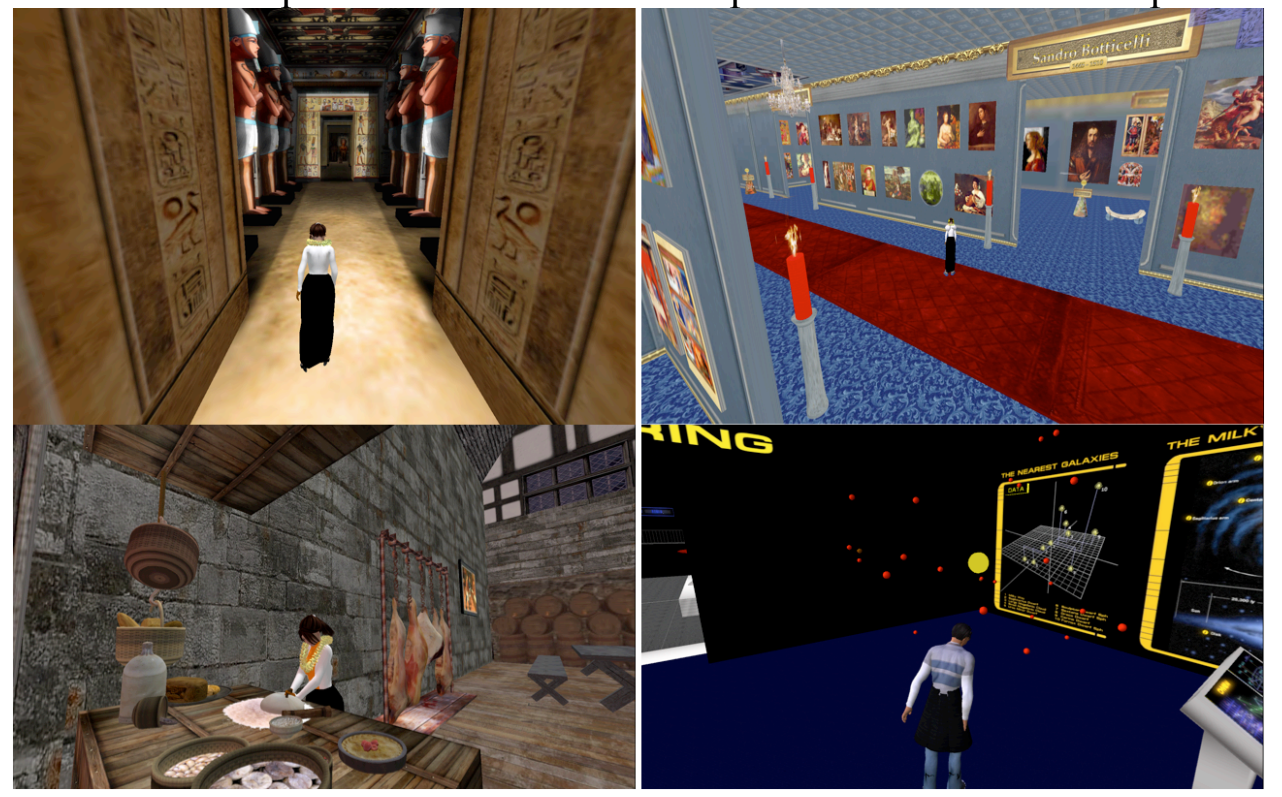

Figure 4. Virtual exploration (from upper left to lower right: Nefertari Tomb on Sunny Breezes - Museum Island, Exploratorium, Comet Classic Paintings Art Gallery, Renaissance Island, Star Trek Museum of Space).

In step 6, participants completed a mid-reflection. Keeping a journal can help educators understand the problems that their own students will encounter in future explorations of 3D IVWs and to design assignments with these issues in mind. Participants thus had an opportunity for deep reflection about their new experiences in an entirely new learning environment. In step 7, groups debriefed their virtual experiences in class by presenting the activities developed in Step 5, including target student population, objectives, rationale, potential modifications to better suit the needs of special education, and a usability rating of each island. Step 8 required participants to analyze an existing lesson plan $^{3}$ about underwater exploration (Imzadi Island). In step 9, groups of three created their detailed special education lesson plan based on the ideas brainstormed in step 5. A lesson plan needed to have at least two elements of inquiry-based learning. Each group then presented their lesson plan to get feedback from their peers and the instructor. In step 10, individual post-reflections were written. Within a week of submitting the reflective journal, participants completed a post-survey (step 11), which included all pre-survey questions as well as 34 additional Likert-type, rating, and open-ended questions. Questions revolved around the usability of SL for education, collaborative learning in SL, and the effectiveness of the SL workshop.

\section{Troubleshooting}

Registering an entire class on SL from the same IP address, for example, is highly problematic. Storey and Wolf (2010) managed to register five students at a time, with the other

\footnotetext{
${ }^{3}$ A repository of SL lesson plans can be found at: http://msitsecondlife.wikispaces.com/Lesson+Plans.
} 
participants having to $\log$ in from home or another spot. Educators who plan to take their students on virtual expeditions need to be prepared for a number of potential technical problems.

\section{Data Analysis}

The study followed a mixed-methods research design, utilizing constant comparative method of data analysis (Glaser \& Strauss, 1967) as well as descriptive and inferential statistics. Data triangulation was achieved through analysis of the various instruments used in steps 1, 3, and 5 through 11. Data describing participants' (pre)conceptions about the use of 3D IVWs for education were synthesized from the instruments used in steps 1, 3, 6, 10, and 11. Data about the participants' ability to reflect critically on the potential uses of 3D IVWs in education and to devise activities and lesson plans supported by a pedagogical rationale were synthesized from steps 5, 7, 8, and 9. The qualitative data were open coded and categorized into recurring themes, which led to the separation of ideas, experiences, and concerns. To achieve investigator triangulation, the authors analyzed the data independently, compared, and ultimately amalgamated the outcomes after discussing discrepancies. The responses to the pre- and postsurveys were compared and analyzed in SPSS. Each individual participant's answers were summed to obtain a total attitude score $(\max .=60)$ regarding their perception of the usability of SL for education. The class means in the pre- and post-surveys were calculated for each presurvey item. To explore the difference in means, a series of dependent $t$-tests and Wilcoxon signed-rank tests were performed.

\section{Survey Reliability}

With respect to reliability, Cronbach's coefficient alpha for the pilot-survey, which was pilot tested on 32 educators, was calculated to be .92. This value indicates a high level of internal consistency among the test items.

\section{Results}

\section{Attitude Scores and Usability Ratings}

Each individual participant's answers were summed to obtain an attitude score (max. = 60) regarding their perception of the usability of SL for education. The class means in the preand post-survey were $42.08(S D=5.14)$ and $40.25(S D=5.26)$, respectively. To explore whether the difference in means was statistically significant and given the small sample size $(\mathrm{N}=12)$ and inability to verify the assumptions required of a parametric test, the Wilcoxon signed-rank test was performed (Table 2) in addition to a dependent-samples $t$-test. Both tests showed that there was no statistically significant difference in mean attitude towards the usability of virtual worlds in education as a result of the workshop. For five items, namely items 6 through 10 , the special education teachers' attitude towards virtual worlds use in education increased. The opposite was true for the remaining seven items. Possible reasons for this outcome will be discussed in a later section. 
Table 2

Means, Standard Deviations, and Results of Wilcoxon Signed-Rank Test for Differences Between Means on the Attitude Survey

\begin{tabular}{|c|c|c|c|c|c|}
\hline \multirow[b]{2}{*}{ Item \# } & \multicolumn{2}{|c|}{ Pre-Survey } & \multicolumn{2}{|c|}{ Post-Survey } & \multirow[b]{2}{*}{$z$} \\
\hline & Mean & SD & Mean & SD & \\
\hline 1 & 3.08 & 1.44 & 2.50 & 1.17 & .31 \\
\hline 2 & 3.08 & 1.31 & 2.92 & 1.08 & .80 \\
\hline 3 & 4.00 & 0.43 & 4.17 & 0.39 & .16 \\
\hline 4 & 2.83 & 1.11 & 3.00 & 1.13 & .73 \\
\hline 5 & 3.92 & 1.00 & 4.00 & 0.74 & .71 \\
\hline 6 & 4.00 & 0.85 & 4.25 & 0.45 & .32 \\
\hline 7 & 4.08 & 0.51 & 4.25 & 0.45 & .42 \\
\hline 8 & 3.75 & 0.75 & 3.50 & 0.80 & .27 \\
\hline 9 & 3.92 & 0.67 & 3.58 & 0.79 & .33 \\
\hline 10 & 3.67 & 0.78 & 3.25 & 1.14 & .16 \\
\hline 11 & 3.17 & 1.11 & 2.83 & 0.94 & .35 \\
\hline 12 & 2.58 & 0.90 & 2.00 & 0.85 & .13 \\
\hline
\end{tabular}

*Statistically significant when the error rate was controlled at the .05 level

Item 13 in the pre-survey and item 26 in the post-survey were identical and asked participants to provide an overall rating of the usability of SL for education on a 10-point rating scale. The mean ratings in the pre- and post-survey were $5.5(S D=1.73)$ and $5.58(S D=1.51)$, respectively. Although the mean rating increased slightly, a dependent-samples $t$-test did not reveal a statistically significant difference between the mean ratings $(p<.05)$.

\section{Mid-Reflection (step 6)}

The responses to each of the four questions will be summarized along with the identification of key themes. Question 1: Why and how should an immersive virtual learning environment be used in special education? Two of the recurring themes strongly overlap with the affordances identified by Dalgarno and Lee (2010), namely experiential learning in situations that would be impossible or impractical in a real life classroom. One special education teacher expressed this thought as, "The game allows students the freedom of stepping out of their own lives and be someone else to explore freely." Another teacher highlighted the experiential affordances of these virtual environments for special education students:

We were looking at the art island and it would give the students a chance to explore an art museum that would not require them to constantly be monitoring behaviors they are not always able to control.

Half of all teachers highlighted the potential of IVWs for special education students with social skills challenges and communication deficits, such as individuals with ASD. Students who lack interactive social skills can learn to collaborate with peers in a safe environment and transfer this new skill to real life situations. It can also enable students with physical limitations to navigate the virtual world like their typically functioning peers. Further themes that emerged included multisensory input (visual, auditory, kinesthetic), which may afford better access to the material when experiencing it in a 3D IVW. Increased motivation and engagement were frequently mentioned as well: "The simple act of learning in a new, exciting way is motivating 
for students." The similarity to video games was pointed out as an additional motivating factor for some students. It was cautioned, however, that it must be considered carefully if content could be better explored in IVWs or the real world and that IVWs should be used to facilitate and expand instruction but not to replace real world instruction completely. Other affordances mentioned include: enhanced spatial knowledge, learning at one's own pace, and making abstract concepts more real.

Question 2: What are some practical ways to use SL for learning and instruction in special education? Creating increased motivation for the learning of topics that might otherwise be perceived as boring ("tuning into the lesson instead of tuning out") and experiencing the impossible or impractical, such as exploring foreign countries, galaxies, star constellations, under the sea environments or past time periods, emerged as the key themes.

Instead of reading them a boring history/science book, start by letting them explore it first hand. Then when you do have to teach follow up lessons, they'll already be interested.

Many of my students beg for computer time and I'd like to incorporate their interests into the learning process. So if we can get on computers and learn some cool things, that is a major bonus.

Virtual environments were considered suitable for a variety of content areas. Science experiments were frequently highlighted. Collaboration emerged as another key benefit. Special education students could use virtual worlds to learn to work collaboratively towards a common goal, namely in ways that they otherwise could not experience in the classroom and with people they otherwise could not work with. The affordances of virtual worlds were often compared with those of video games where gamers work in teams to complete missions. One teacher highlighted the benefit of stress-free collaborative excursions: "Interacting with peers in different islands can get children to explore new topics together. Second Life makes 'fieldtrips' hasslefree." Social skills and communication practice were mentioned as affordances for students with social and communicative deficits, such as individuals with severe language delay, English language learners, and shy students.

Question 3: Overall, do you think Second Life will motivate students to participate more actively, to make efforts more willingly, and to become more involved in learning activities? Please explain. Most participants agreed that anything involving computers gets students excited about learning since they think it is a game, which was perceived as being useful for topics that students are not normally interested in. Again, SL was compared with popular video games. Collaboration through technology was identified as another key benefit.

I also think that Second Life would make group work more appealing as I have witnessed the agony of group work contrasted by how my students will help each other get a new app or to figure out the controls of a new game.

Anonymity and autonomy could be additional benefits because they might help students to participate more willingly and become more involved in learning.

Many students would enjoy the autonomy that SL affords which they normally don't have in a regular classroom.

Small things like having absolute control over your own avatar and your own actions might be an incentive for students who feel shy and insecure in the classroom. 
Competition was identified as another way to take advantage of virtual environments. Cautionary comments, however, were made about the required computer literacy, the lack of which could easily lead to frustration.

I found myself getting quite frustrated and would have easily given up on the program if I was not intrinsically motivated to succeed. Many of our students do not have that same drive.

Virtual environments could also be problematic for students with poor eye-hand coordination who may get frustrated with navigation and students with less patience may get annoyed when waiting for parts of SL to load. Continuous student support was considered a prerequisite for any successful virtual activity.

Much guidance, assignments broken down in chunks, and very clear directions will be needed to help students navigate learning activities that incorporate Second Life.

Question 4: Overall, in your own words, how would you rate the potential of SL for learning and instruction? Fifty percent of the participants described SL as having strong potential for education while 33\% rated it as moderately useful. Seventeen percent were undecided. Several concerns were voiced, such as the amount of effective teacher and student preparation and coping with accessibility issues. Some participants found the visual stimulus and the large spaces overwhelming. A lack of information, such as in the form of interactive information displays or note cards, was another concern.

The system visually and settings-wise would be too overwhelming for students in elementary school. [...] I found that a lot of time was wasted wandering around looking at places and items that had no information to explore. I would have to pick very specific worlds to use--worlds that are well-designed and highly effective in instruction.

It was mentioned that its use could be difficult for various student groups, such as those with less patience, those who dislike computers, those with physical impairments that make it difficult to see the screen or manipulate the keyboard/mouse. But once these various issues were resolved, there could be considerable potential for an engaging collaborative platform.

It would also be a large time commitment to find the worlds that would be most beneficial to the students and to keep them away from those that are not. But once teacher and students are acclimated to the system, I think it would be a great tool for learning. It is incredibly engaging and fun just to explore with a lot of potential for motivation and collaboration. And those are two things that my students struggle with.

\section{Lesson Plan Analysis (Step 8)}

In this activity, the special education teachers analyzed an existing lesson plan revolving around Imzadi Island. After doing the virtual scuba diving tour in teams of three, they discussed four prompts. The identified four key affordances, which confirm those identified earlier, namely increased engagement/motivation, opportunities for collaboration, spatial representation, and experiential learning. Several suggestions were made how to modify the lesson plan to better accommodate the needs of special education students, namely by eliminating the text chat, replacing SL animals by real life images, having the teacher navigate so students do not get frustrated, and labeling the marine life to help with identification. Participants anticipated several 
challenges, such as unpleasant outside influences, difficulties with computer usage, age limits, misuse of the program and equipment, ending up in the wrong place, and difficulty navigating. One group mentioned that there was not enough to learn to justify the extensive amount of time needed to set up SL and learn to navigate it. Finally, it was feared that it would be challenging to monitor all students at the same time.

\section{Lesson Plan Development (Step 9)}

Lesson plans were developed in groups of three. Appendix 2 displays one of the lesson plans developed in the area of astronomy and chemistry for an earth science class. The topic is space and elements. The group's rationale was to provide students with an opportunity to travel in space and to explore stars, black holes, and galaxies as if they were part of the Star Trek crew. The SL location is the Star Trek Museum of Science. The lesson is intended to help students apply what they have previously learned in class and is designed as a scavenger hunt to increase student engagement.

\section{Post-Reflection (Step 10)}

The responses to each of the five prompts will be summarized along with the identification of the key themes. Question 1: What are some of the affordances and challenges you encountered during your familiarization with Second Life? Similar to the mid-reflection, participants agreed that virtual worlds have great potential for experiential learning and that social interaction practice would be particularly suitable for students with social issues. "Kids love technology and this type of exploration will satisfy their needs." The most frequently mentioned challenges were frustrations due to a slow internet connection, crashes/getting logged out, getting stuck, difficulties navigating, lack of user friendliness, becoming overwhelmed because there was too much to explore, and getting easily distracted from the task at hand due to visual stimuli.

Question 2 (third research question): What guidelines would you establish for teachers when they incorporate $3 D I V W s$ in their own teaching? Understanding how Second Life works before having the students dive in was frequently mentioned. It was recommended that teachers not only try out the lesson ahead of time but also try having so many people logged in at the same time. The class should be isolated from other people's avatars to prevent unpleasant encounters.

You would have to teach explicit steps and assess students' technological aptitude and computer literacy before proceeding with any assignments. Content filters should also be carefully looked at and appropriately set. You would also have to have an activity in clear, simple steps and give students ample time and direction to complete their work. They would also need a good amount of time to play and explore before any tasks are assigned.

Distraction was a frequent concern. One participant recommended: "Have a learning objective and stick to it." Teachers were advised to encourage creativity based on the unique affordances of virtual worlds: "This is the time for them to get creative and explore things that you wouldn't normally be able to explore because of different limitations."

Question 3 (first research question): How can we best train special education teachers for the use of Second Life in their own teaching? The following key recommendations emerged: 
engage teachers in extensive virtual experience, provide sample lesson plans for different ages and subjects, analyze and develop lesson plans, learn how to locate content-specific SL islands for specific age groups, and work with a more experienced peer coach or facilitator.

Teach how to use it as an effective supplement or alternative to direct instruction.

Teach explicitly over an extended period of time so that teachers can use this with confidence and pass that on to students. This would make it time efficient and minimize frustration for students and teachers.

Question 4: What should an ideal SL island for special education look like? What features would you like to see? (Imagine making recommendations for SL designers and developers.) Again, social interaction emerged as one of the key themes, for example "a social setting that shows students how to behave would be helpful for ASD students". Practical ideas of what should be possible on a virtual island include: practicing daily tasks (e.g., going to the store), conducting job interviews, educational games (e.g., game show area for trivia and facts), social interaction game or practice area, and "online role plays similar to social stories so that kids can learn behaviors". A Career Island would be beneficial for high school students getting ready for transition. Islands should be small, streamlined, and very specific to the content covered, with things easy to find in a user-friendly environment where everything is labeled.

Question 5: Overall, if you consider the affordances and challenges of SL for educational purposes (see charts), do you consider using SL in your own classroom? The participants were equally divided into three categories: yes, maybe, and no. Reasons for those who stated they would not (currently) consider using SL included: comfort level of using SL too low, school technology insufficient, too many variables to control at once, and students lacking the prerequisite level of computer awareness. Those in the "maybe" category stated that they might use it if there was a SL "junior" version" or if they could "develop a structured social component to align with content we are currently studying".

\section{Post-Survey (step 11)}

The results of items 1 through 12 were equivalent to the pre-survey and have already been reported. The key responses to the remaining items will be briefly summarized. Participants agreed that learners neither had to be particularly independent $(100 \%)$ nor intrinsically motivated $(92 \%)$ to use SL for learning. A majority (58\%), however, agreed that SL was only suitable for learners with high technology skills. Similarly, navigation was perceived as difficult by all but one (92\%). Most (92\%) liked that they could manipulate objects in SL and agreed that the game style $(92 \%)$ and rich landscape $(67 \%)$ were motivating. A majority $(58 \%)$ would be willing to use SL for teaching together with an experienced SL coach, co-teacher or facilitator. A minority $(25 \%)$ feared that they lacked the necessary technical skills even though they would actually like to use SL for teaching. When asked which educational activities (from a selection of options) they considered suitable for their class, treasure hunts clearly emerged as the most preferred option (67\%); followed by historical recreations (58\%), such as Atlantis, Land of Lincoln, Paris in 1900 as well as cultural immersion (58\%), such as virtual Morocco. Data visualizations and displays/exhibits were each chosen by $50 \%$. The least favored options (33\% each) were selfpaced tutorials, immersive exhibits (e.g., an exhibit that leads visitors through the minds of schizophrenic patients), language learning, and creative writing. All but one participant (92\%) appreciated that the assignments were designed as collaborative events. It was suggested that

\footnotetext{
${ }^{4}$ Second Life Teen is no longer available. 
"the assignment [in this workshop] was a little too open and may have been more beneficial if we had been grouped by grade level/subject matter." Nevertheless, having partners enhanced the experience of exploring a novel environment and helped to overcome the frequently encountered technical hurdles.

I think that the learning experience and the outcome was much better working in groups than it would have been alone. I see the validity of the assignment but I would have been very frustrated with the experience if I had to work on it alone. SL was a little difficult for me to navigate and even logging on was tough at times. I would have not been motivated or invested without working in a group. I think this was a great group project.

Half of the participants enjoyed the partner work very much and stated that the collaboration had motivated them to put in greater efforts than if they had been working alone. The final comments addressed what could have been done to improve the workshop. First, it was suggested that the other groups try out the lesson plans developed in step 9 so that suggestions for implementation could be included in the revisions. Second, the lack of a fast and solid internet connection in the computer laboratory was frequently mentioned as making the experience less enjoyable.

\section{Discussion}

This study offered special education teachers a semester-long opportunity to engage in and familiarize with the new digital literacies of 3D IVWs while reflecting on their usability critically and purposefully. Similar to studies conducted by Campbell (2009), Dickey (2011), and Guzzetti and Stokrocki (2013), these participants became familiar with educational resources in SL and planned activities that would offer learning affordances that students could not otherwise benefit from. Based on the results, the discussion is developed around the key themes that emerged from the qualitative analysis, namely using virtual worlds as a collaborative platform for social skills practice in special education settings, the potential of virtual worlds for motivation purposes, and various challenges. The section will conclude in a comparison of the quantitative results of this study with those of a pilot study.

The current findings provide support for the notion that virtual environments are valuable for special education. Several participants pointed out the benefits of social skills practice for students with social skills challenges, such as students with autism. Using virtual worlds to practice life skills and teach empathy have been widely reported (e.g., deAngelis, 2009; FusarPoli et al., 2008; Mitchell et al., 2006; Moore et al., 2005; Newbutt \& Donegan, 2010). The participating special education teachers suggested that educators receive extensive training in order to build enough confidence to teach in virtual worlds and to be informed about options of virtual spaces across different ages and subjects. Silva, Correia, and Pardo-Ballester (2010) may serve as a model of a semester-long collaborative effort to develop a solid understanding of how SL can be used in teacher education. Guidelines in Edirisingha, Nie, Pluciennik, and Young (2009) on how to develop learning activities that facilitate social presence and socialization among distance learners for collaborative learning in SL may also assist special educators in the design of social skills practice activities.

Visual stimuli were perceived with ambivalence. Similar to the participants in a study by Omale, Hung, Luetkehans, and Cooke-Plagwitz (2009), the special education teachers participating in the current study suggested that visual stimuli may be overwhelming and 
distracting from learning, possibly to the extent that "learning was not enhanced and technology became a distraction rather than an enabler" (Omale et al., 2008, p. 492). Other distractions can be the design of an avatar (Dickey, 2011). The same visual details that can be appealing to some users may be perceived as distracting by others. Which kind of experiences and perceptions enhance and distract from a positive experience in virtual worlds has been addressed in detail in Jamison (2008).

Participants frequently stated that the similarity of SL to a game might increase students' willingness to participate actively and get involved in the learning process more willingly. This similarity to a game, however, is deceiving. Despite some similarities, SL is not a game. Students might perceive virtual worlds as spaces for play rather than educational environments (Cheal, 2009) and could be disappointed when they realize that virtual worlds, such as SL, have not been designed as games and fail to offer the same affordances. Cheal (2009) also reported that students became uncomfortable with the open-ended creative potential of SL, which is also in line with the challenges identified in this study. According to the Horizon Report (2012), games offer several affordances for education, such as the feeling of working toward a goal, the possibility of attaining spectacular successes, the ability to problem solve and collaborate with others, and an interesting story line. Even though these qualities may be adapted to educational content, the design challenges may be difficult to overcome and costly (Horizon, 2012).

Several participants were concerned about their students being exposed to inappropriate content or adult content or having unpleasant encounters with griefers who irritate and harass other users. Educators' concerns about security issues have been widely reported (e.g., Cheal, 2009; Dickey, 2011, Kirriemuir, 2010). Unless an educator has access to a privately owned island, there is always a risk of unpleasant encounters, even on islands designated "General". General maturity rating means that a region is "not allowed to advertise or make available content or activity that is sexually explicit, violent, or depicts nudity" (Second Life Knowledge Base, 2013). But a general maturity rating (as opposed to moderate or adult) does not prevent griefers from harassing other users, even on islands with a clearly educational purpose. As can be seen in the Second Life Educational Directory, many educational islands have a moderate maturity rating and so do several of the islands used in this study. It is recommended that educators using SL with students continuously monitor their students' activity and virtual location. For this purpose, it is advisable to have one or two facilitators. Students should be prepared for possible instances of grieving and how to react (e.g., right-click on griefer's avatar and report to Linden Lab). Participants in this study did not report any instances of griefing or any other unpleasant experiences.

Locating appropriate and content-specific virtual spaces was another frequently raised concern. Not all educators have access to a university-owned island and may have to use public islands. Some publicly accessible but unlisted educational spaces are announced in a listserv for SL educators (SLED). One example of such a virtual space is the virtual wet lab in SL that is owned by Prince William Sound Community College ${ }^{5}$. Another experimental laboratory set up in SL is owned by the University of Leicester, $\mathrm{UK}^{6}$. Some participants in the current study doubted that the learning benefits of using virtual worlds, such as SL, justify the extensive amount of time that would be needed for teacher and student preparation. The qualitative

\footnotetext{
${ }^{5}$ for an overview of the lab: http://www.pwscc.edu/academics/creative-learning-in-a-virtual-wet-lab/

${ }^{6}$ for a tour of the lab: http://www2.le.ac.uk/projects/swift
} 
analysis of this study revealed an almost balanced ratio between perceived affordances and challenges for both general and special education settings (Table 3 ).

Table 3

Perception of Affordances and Challenges of SL

\begin{tabular}{ll}
\hline Benefits & Challenges \\
\hline Platform for social skills practice & $\begin{array}{l}\text { Amount of teacher and student preparation } \\
\text { Accessibility issues (e.g., internet connection, crashes, } \\
\text { Experiential learning (e.g., science experiments, cultural } \\
\text { immersion) }\end{array}$ \\
$\begin{array}{l}\text { graphic card) } \\
\text { Poor eye-hand coordination impairs navigation }\end{array}$ \\
Increased motivation & Safety issues (exposure to strangers) \\
Learning at own pace/increased student autonomy & Lack of required computer literacy \\
Spatial representation & Deceptive similarity to video games \\
Making abstract concepts more real & Visually overwhelming, distracting from learning \\
Multi-sensory input & \\
Anonymity encourages shy students to participate more & \\
\hline
\end{tabular}

How educators perceive the usability of 3D IVWs for education will likely influence how they will implement virtual spaces into their teaching. Dickey (2011) cautioned that virtual worlds are not value-neutral, each having its affordances and drawback. Most teachers in a study by Dickey (2011) highlighted the importance of developing virtual tools to meet the needs of teachers and students rather than "forcing" teachers into using existing tools. As virtual worlds become more popular in education, more schools and colleges of education will want to offer virtual worlds teacher training. Ideally, such a workshop would not only address the rationale of using virtual worlds (i.e., their unique affordances), as was repeatedly done in the present study, but also explicitly guide educators through each step of virtual teaching, that is, how to teach inworld. Providing sample lesson plans for different ages and across subject matters might help alleviate teachers' fears of an extensive time commitment in terms of preparation.

The quantitative analyses in this study failed to show statistically significant differences between the mean attitude scores collected in the pre- and post-survey. This finding is in contrast to the results of a pilot study by the same authors (Nussli \& Oh, under review), which suggested a statistically significant increase in mean attitude with a large effect size as a result of the training participants received in SL $(z=3.30, p<.05, r=.54)$. The pilot study was much shorter with fewer steps (three weeks/7 steps vs. three months/11 steps in the current study); the participants were pre-service general education teachers with some teaching experience (vs. inservice special education teachers in the current study); and the virtual explorations were done from participants' home computers with stable, fast internet access, and the use of Skype for voice communication (vs. sessions at the computer laboratory in the current study, with 12 participants logged in simultaneously, resulting in a significant slow down and numerous crashes). For some of the group work, only one participant was navigating SL while the other group members were observing and brainstorming on ideas for activities. The authors can only speculate that this combination of factors caused a failure to produce a more positive attitude change in the participants. Based on these factors, it is recommended that participants log into SL from different locations to ensure fast and stable access with use of Skype for voice communication to ensure high voice quality and that group work is designed in a way that each group member is logged in and navigating/exploring rather than having one navigator and 
several passive observers. If participants must log in simultaneously from the same physical location, the number of participants should be low, which clearly makes SL less practical and appealing for use with regularly sized classes. It is also recommended that a large number of avatars avoid congregating in the same area because this could cause low frame rates and unresponsive controls, as experienced in this study.

In sum, the findings of this study suggest the following components of effective virtual worlds teacher training, which are in line with the findings of Nussli \& Oh (under review): (a) scaffolded introduction to a 3D IVW, (b) collaborative explorations framed by a pedagogical rationale and self-reflection, (c) identification of unique affordances, (d) having students design learning activities framed by a pedagogical rationale, (e) assistance of a more experienced inworld facilitator to help teachers acquire the unique skills required to become a successful virtual teacher, and (f) learning how to locate subject matter directories in-world. In addition, it is recommended that teacher educators model effective teaching in 3D IVWs (Nussli \& Oh, in press).

There are a number of limitations to the present study. The preliminary survey did not include questions examining the participants' specific technological background and use of technology both in their teaching and at home. Collecting these data would have allowed the authors to correlate the participants' technology use and expertise with their preconceptions of 3D IVWs. Although the sample of twelve participants is small $(\mathrm{N}=12)$, it seems adequate compared with similar studies. The sample sizes in studies with similar purposes (e.g., Annetta et al., 2008; Blankenship \& Kim, 2012; Dickey, 2011; Edirisingha et al., 2009; Gamage et al., 2011; Good et al., 2008; O'Connor, 2009-2010; O'Connor \& Sakshaug, 2008-2009; Omale et al., 2009; Silva et al., 2010; Storey \& Wolf, 2010) range from two to 41, with only three studies having more than 13 participants. Finally, although the special education teachers in the present study explored SL exclusively, it can be assumed that the results can be generalized to other comparable 3D immersive virtual environments due to the similarity of features, namely an interactive, open-ended environment with avatars for visual representations of the users and a chat tool for communication.

\section{Conclusions}

The overarching goal of this study was to increase special education teachers' awareness of the potential of $3 \mathrm{D}$ technologies for learning and instruction. The practical significance of this study is that it will assist educators and teacher educators in developing an understanding of the pragmatics of integrating 3D technology in their teaching. Throughout the study, the special education teachers were challenged with the task of transferring the skills and experiences they all encountered to the task of implementing 3D IVWs in their classrooms. Although these teachers were able to navigate through 3D IVWs after a short training session, a thorough training with more practice was expected to provide a more valuable overall experience. While immersed in a virtual world, the teachers were able to collaborate with other teachers in inquirybased learning activities. The results revealed that these 12 teachers agreed on 3D IVWs providing experiences that their students may not be able to encounter in real life. Special potential was identified for social skills practice, observation of modeled behavior as well as collaborative and experiential learning. The potential for this technology in a classroom setting seems limitless. Its practical implementation, however, requires that teachers receive appropriate training that builds both their confidence in their virtual teaching skills and their commitment 
towards using 3D technology in a classroom. Overall, despite technical issues, the findings of this study suggest that 3D IVWs are a valuable tool to complement face-to-face teaching, especially in special education.

Academic professionals can be expected to have a good command of digital media literacy so that they can support learners in developing digital media literacy skills (NMC Horizon, 2012). Due to the limited amount of training, however, teachers often feel that they lack technical support, the skills, or a pedagogical rationale for using technology in their teaching (NMC Horizon, 2012). Hence, they may be entering a classroom with a pre-existing attitude toward technology that may or may not be favorable as a result of the pre-service training. It has been widely acknowledged that the transition from traditional to virtual teacher requires stamina, modeling, scaffolding, and continuous mentoring (e.g., Alvarez, Guasch, \& Espasa, 2009). Colleges of Education are encouraged to consider offering innovative courses specifically targeted towards virtual education. Teachers' buy-in to the use of 3D IVWs, however, may be intricately linked with effective teacher training. Therefore, if teachers are not convinced of the need of 3D IVWs for educational purposes, even the best training is likely to fail. As a result, one of the key steps is to secure teachers' acknowledgment of the validity of 3D IVWs for education. Immersing teachers in virtual experiences will help them make informed decisions.

\section{Future Research}

The potential for future work examining effective teacher training in the use of 3D IVWs for both general and special education is striking. Researchers are encouraged to investigate the needs of special education teachers and students to improve the design of virtual spaces designed specifically around these needs. Further research into teachers' perceptions of the value of 3D IVWs for education and how these perceptions impact their virtual teaching practice will advance our understanding of the unique affordances and drawbacks and will help design these spaces in a way that they support learning. As 3D teaching is becoming increasingly popular, researchers are encouraged to continue to build on best practices of virtual worlds teacher training. More research is needed to show if and how 3D IVWs provide advantages over other pedagogical techniques and how to exploit their potential (Dalgarno \& Lee, 2010). These findings will further inform effective teacher training that will enhance the learners' experience in 3D IVWs and increase their knowledge of how to implement this technology into their teaching. Currently in teacher education, 3D IVWs are used sparingly. The understanding of the technology has not been established, but once in-world teaching becomes more popular, teacher educators will develop the ability to model effective uses of 3D IVWs to pre-service and inservice teachers while sharing best practices as they continue to experiment. 


\section{Appendices}

Appendix 1: Project Overview: 11 Steps

\begin{tabular}{lll}
\hline$\#$ & Description of Activity \\
\hline 1 & $\begin{array}{l}\text { Watch Youtube video NOAA and } \\
\text { complete pre-survey on Survey } \\
\text { Monkey }\end{array}$ \\
2 & SL start-up \\
3 & $\begin{array}{l}\text { Individual fieldtrip after watching a 7- } \\
\text { minute demo video }\end{array}$ \\
4 & $\begin{array}{l}\text { Read about unique affordances of 3D } \\
\text { IVWs in Dalgarno and Lee (2010) }\end{array}$ \\
5 & Virtual Exploration - Group activity \\
& & Mid-reflection \\
7 & $\begin{array}{l}\text { Presentation of findings (conclusions } \\
\text { formed in Step 5) }\end{array}$
\end{tabular}

8 Analyzing an existing SL lesson plan (Imzadi Island)

9 Collaborative development of a lesson

10 Post-reflection

11 Complete post-survey
Rubric

\section{Assess- \\ Inquiry-Based Learning Cycle*} ment

Preliminary

survey

submitted

Observation in step 3

Screenshots submitted

In-class review Observation of in-class participation Rubric

In-class presentation

In-class participation

Rubric

Post-survey submitted evidence. in SL. initiate virtual experience. next task. will be instrumental in this step.

same as step 10
Inquiry starts with open-ended question for investigation: "How usable is SL for general and special education purposes?" Complete all inquiry steps to come to a conclusion supported by adequate

Demonstrate personal investment and active engagement into the investigation of 3D IVWs by proactively spending time (at participants' discretion)

Collaborate with peers and demonstrate readiness to

Acquire background knowledge to get ready for

Engage in an extensive hands-on virtual experience by planning and conducting their own group investigation of the usefulness of SL for education. Express, clarify, justify, and represent ideas.

Make an informed decision about the usability of these specific islands by giving priority to evidence and formulating explanations from this evidence. Communicate and justify explanations.

Connect previous exposure to SL and insights gained from class discussions with an analysis of an existing lesson plan based on SL. Examine and critique the rationale for the activity, the design of the lesson plan, and reflect on its usability for special education. Insights from the previous steps will culminate in the development of a final product, which should be representative of participants' revised beliefs about the educational potential of 3D IVWs. Communicate and justify final product and connect rationale with knowledge gained in this workshop. Peer feedback

Express, clarify, justify, and represent ideas. At this point, participants should be able to make an informed decision about the usability of SL for special education purposes by providing substantiated evidence. Based on their insights, participants should also be able to describe an ideal SL island, thereby completing the cycle in the investigation about the potential of SL.

\footnotetext{
* adapted from "Essential features of classroom inquiry and their variations" (National Research Council, 2000).
} 


\section{Appendix 2: Lesson Plan Samples Developed by Special Education Teachers}

\section{Learning Students will be able to:} objectives

- Identify the planets in our solar system

- Identify the three closest stars to the sun

- Identify key attributes of the three closest stars to the sun (size, appearance, properties)

- Define a black hole (what it is, how big it is, how it forms, where they are in space)

- Identify properties of copper, barium, potassium, and atom

- Using the periodic table, identify element names, atomic number, and states of matter

Procedures A. Find the hologram of our solar system. Draw a model of the planets in our solar system.

B. Name the 3 closest stars in the Milky Way Galaxy to our sun. Name each star and tell how many light years away each start is from the sun.

C. What is a black hole?

D. Name all the planets with rings.

E. What is an atom? Draw the atom model you see in SL. Name three aspects of an atom.

F. Go to Tovadock Science Institute room. Play with the Bunsen burner and elements. What color flame do the following elements create: Copper, barium, potassium?

G. In the periodic table, find the element whose symbol corresponds to Ms. N.'s first name (ask for her name nicely!). What is this element's full name? What is the atomic number? Is this element's natural state? (i.e. liquid, gas, or solid?)

After getting a 1st, 2nd, and 3rd winner, the class will re-convene and review the answers to each card. The class will then discuss which parts of the museum they liked and how it helped them understand astronomy and/or chemistry better.

Students will write a one-page reflection about what they learned about astronomy and/or chemistry.

Evaluation
strategies

Adaptations

Anticipated challenges

Screenshot
- Students' answer sheets

- After the lesson, students will be assigned a one-page reflection on what they have learned during the scavenger hunt.

- Shorten the amount of objects in the scavenger hunt.

- Focus on very easy to find stations such as the telescope and Bunsen burner.

- Guide students through the lesson on own computer connected to a projector.

- For students unfamiliar with Star Trek, it might be a bit challenging to identify the real world science scattered among "warp technology".

- The area is very large so students may get lost and be unable to find the above locations. 


\section{References}

Alvarez, I. I., Guasch, T. T., \& Espasa, A. A. (2009). University teacher roles and competencies in online learning environments: A theoretical analysis of teaching and learning practices. European Journal of Teacher Education, 32(3), 321-336. doi: 10.1080/02619760802624104

Baker, S. C., Wentz, R. K., \& Woods, M. M. (2009). Using virtual worlds in Education: Second Life[R] as an educational tool. Teaching of Psychology, 36(1), 59-64. doi: $10.1080 / 00986280802529079$

Balcikanli, C. (2012). Language learning in Second Life: American and Turkish students' experiences. Turkish Online Journal of Distance Education, 13(2), 131-146.

Barab, S. A., Hay, K. E., Barnett, M., \& Keating, T. (2000). Virtual solar system project: Building understanding through model building. Journal of Research in Science Teaching, 37(7), 719-756. doi: 10.1002/1098-2736(200009)37:7<719::AID-TEA6>3.0.CO;2-V

Barab, S. A., Sadler, T. D., Heiselt, C., Hickey, D., \& Zuiker, S. (2010). Erratum to: Relating narrative, inquiry, and inscriptions: Supporting consequential play. Journal of Science Education and Technology, 19(4), 387-407. doi: 10.1007/s10956-010-9220-0

Barbour, M. K., \& Reeves, T. C. (2009). The reality of virtual schools: A review of the literature. Computers and Education, 52, 402-416. doi: 10.1016/j.compedu.2008.09.009

Blankenship, R., \& Kim, D. (2012). Revealing authentic teacher professional development using situated learning in virtual environments as a teaching tool. International Forum of Teaching Studies, 8(1), 36-53.

Blasing, M. T. (2010). Second language in Second Life: Exploring interaction, identity and pedagogical practice in a virtual world. SEEJ, 54(1), 96-117.

Chapman, D. D., \& Stone, S. J. (2010). Measurement of outcomes in virtual environments. Advances in Developing Human Resources, 12(6), 665-680. doi: 10.1177/1523422310394792

DeAngelis, T. (2009): Can Second Life therapy help with autism? American Psychological Association, 40(8), 40.

Dalgarno, B., \& Lee, M. J. W. (2010). What are the learning affordances of 3-D virtual environments? British Journal of Educational Technology, 41(1), 10-32. Software: Practice and Experience, 39, 1015-1054.

Dickey, M. D. (2011). The pragmatics of virtual worlds for K-12 educators: Investigating the affordances and constraints of Active Worlds and Second Life with K-12 in-service teachers. Educational Technology Research Development, 59, 1-20. doi: 10.1007/s11423-010-9163-4

Edirisingha, P., Nie, M., Pluciennik, M., \& Young, R. (2009). Socialisation for learning at a 
distance in a 3-D multi-user virtual environment. British Journal of Educational Technology, 40(3), 458-479. doi: 10.1111/j.1467-8535.2009.00962.x

Fetscherin, M., \& Lattemann, C. (2008). User acceptance of virtual worlds. Journal of Electronic Commerce Research, 9, 231-242.

Fusar-Poli, P., Cortesi, M., Borgwardt, S., \& Politi, P. (2008). Second Life virtual world: A heaven for autistic people? Medical Hypotheses, 71(6), 980-1. doi: 10.1016/j.mehy.2008.07.024

Gamage, V., Tretiakov, A., \& Crump B. (2011). Teacher perceptions of learning affordances of multi-user virtual environments. Computers \& Education, 57, 2406-2413.

Glaser, B. G., \& Strauss, A. (1967). The discovery of grounded theory. Chicago: Aldine.

Grant, S., \& Clerehan, R. (2011). Finding the discipline: Assessing student activity in Second Life. Australian Journal of Educational Technology, 27(5), 813-828.

Good, J., Howland, K., \& Thackray, L. (2008). Problem-based learning spanning real and virtual worlds: A case study in Second Life. ALT-J, Research in Learning Technology, 16(3), 163-172. doi: 10.1080/09687760802526681

Gorini, A., Gaggioli, A., Vigna, C., \& Riva, G. (2008). A Second Life for eHealth: Prospects for the use of 3-D virtual worlds in clinical psychology. Journal of Medical Internet Research, 10(3). doi: 10.2196/jmir.1029

Guasch, T., Alvarez, I., \& Espasa, A. (2010). University teacher competencies in a virtual teaching/learning environment: Analysis of a teacher training experience. Teaching and Teacher Education, 26, 199-206. doi: 10.1016/j.tate.2009.02.018

Guzzetti, B., \& Stokrocki, M. (2013). Teaching and Learning in a Virtual World. E-Learning, $10(3), 242-259$.

Harlow, D., \& Nilsen, K. (2011). Virtual inquiry experiences. Science \& Children, 49(4), 42-45.

Ishizuka, H., \& Akama, K. (2012). Language learning in 3D virtual world - Using Second Life as a platform. E-learning and Education, 1(8).

Jackson, R. L., \& Fagan, E. (2000). Collaboration and learning within immersive virtual reality. Proceedings of the third international conference on Collaborative VLES CVE 00, 83-92. ACM Press.

Johannesen, M. (2013). The role of virtual learning environments in a primary school context: An analysis of inscription of assessment practices. British Journal of Educational Technology, 44(2), 302-313. doi: 10.1111/j.1467-8535.2012.01296.x

Kandalaft, M. R., Didehbani, N., Krawczyk, D. C., Allen, T. T., \& Chapman, S. B. (2013). 
Virtual reality social cognition training for young adults with high-functioning autism. Journal of Autism and Developmental Disorders, 43, 34-44. doi: 10.1007/s10803-012-1544-6

Knutzen, B., \& Kennedy, D. (2012). The global classroom project: Learning a second language in a virtual environment. The Electronic Journal of e-learning, 10(1), 90-106.

Lin, J., \& Tallman, J. (2006). Theoretical framework for online inquiry-based learning. Technology and Teacher Education Annual, 2, 967-974.

Mayrath, M. C., Traphagan, T., Heikes, E. J., \& Trivedi, A. (2011). Instructional design best practices for Second Life: A case study from a college-level English course. Interactive Learning Environments, 19(2), 125-142. doi: 10.1080/10494820802602568

Mitchell, P., Parsons, S., \& Leonard, A. (2007). Using virtual environments for teaching social understanding to 6 adolescents with autistic spectrum disorders. Journal of Autism and Developmental Disorders, 37(3), 589-600.

Moore, D., Cheng, Y, McGrath, P., \& Powell, N. (2003). Collaborative virtual environment technology for people with autism. Focus on Autism and Other Developmental Disabilities, 20 , 231-243.

Mroz, A. (2012). Négociation et co-construction du sens en français langue étrangère (FLE) lors d'une immersion dans un environnement virutel d'apprentissage (EVA). Canadian Modern Language Review, 68(4), 359-392.

National Research Council. (1996). The National Science Education Standards. Washington, DC: The National Academy Press.

National Research Council (2000). Inquiry and the national science education standards: A guide for teaching and learning. Washington D.C: National Academy Press.

Nelson, B. C., \& Ketelhut, D. J. (2007). Scientific inquiry in educational multi-user virtual environments. Educational Psychogical Review, 19, 265-283. doi: 10.1007/s10648-007-9048-1

Newbutt, N. A., \& Donegan, M. (2010): A brief review: Assistive technology and autism, a proposal for virtual tools for improved communication and emotional recognition. In: Society for Information Technology \& Teacher Education (SITE) 2010 21st International Conference, 31 March 2010, San Diego, CA, United States. (Unpublished)

Nishimura, H., Lim, K. Y. T., \& Koyamada, K. (2012). The Abyss Observatory designing for remote collaboration, self-directed discovery and intuition development in multi-user interactive 3D virtual environments. Journal of Virtual Worlds Research, 5(2).

NMC Horizon Report (2012). Higher Education Edition. Retrieved from http://www.nmc.org/publications/horizon-report-2012-higher-ed-edition 
Nussli, N., \& Oh, K. (in press). The components of effective teacher training in the use of threedimensional immersive virtual worlds for learning and instruction purposes: A literature review. Journal of Technology and Teacher Education.

O’Connor, E. A. (2009-2010). Instructional and design elements that support effective use of virtual worlds: What graduate student work reveals about Second Life. Journal of Educational Technology Systems, 38(2), 213-234.

O’Connor, E.A., \& Sakshaug, L.E. (2008-2009). Preparing for Second Life: Two teacher educators reflect on their initial foray into virtual teaching and learning. Journal of Educational Technology Systems, 37(3), 259-271

Omale, N., Hung, W.-C., Luetkehans, L, \& Cooke-Plagwitz J. (2009). Learning in 3-D multiuser virtual environments: Exploring the use of unique 3-D attributes for online problem-based learning. British Journal of Educational Technology, 40(3), 2009.

Pérez-García (2009). MUVEnation: A European peer-to-peer learning programme for teacher training in the use of MUVEs in education. British Journal of Educational Technology, 40(2), 561-567.

Rothfarb, R., \& Doherty, P. (2007). Creating museum content and community in Second Life. In J. Trant and D. Bearman (Eds.), Museums and the Web 2007: Proceedings. Toronto: Archives \& Museum Informatics. Retrieved July 20, 2013 from:

http://www.archimuse.com/mw2007/papers/rothfarb/rothfarb.html

Salt, B., Atkins, C., \& Blackall, L. (2008). Engaging with Second Life: real education in a virtual world. Retrieved August 27, 2013 from: http://piensl.pbworks.com/f/slliteraturereviewa1.pdf

Second Life Knowledge Base (2013). Maturity ratings. Retrieved August 14, 2013 from http://community.secondlife.com/t5/English-Knowledge-Base/Maturity-ratings/tap/700119\#What_are_maturity_ratings.3F

Silva, K., Correia, A., \& Pardo-Ballester, C. (2010). A faculty mentoring experience: learning together in Second Life. Journal of Digital Learning in Teacher Education, 26(4), 149-159.

SLED (2013). SL Educators. Retrieved August 14, 2013 from https://lists.secondlife.com/cgibin/mailman/listinfo/educators

Stendal, K., Balandin, S., \& Molka-Danielsen, J. (2011). Virtual worlds: A new opportunity for people with lifelong disability? Journal of Intellectual \& Developmental Disability, 36(1), 80-83. doi: $10.3109 / 13668250.2011 .526597$

Storey, V. A., \& Wolf, A. A. (2010). Utilizing the platform of Second Life to teach future educators. International Journal of Technology in Teaching and Learning, 6(1), 58-70.

Strickland, D. (1996). A virtual reality application with autistic children. Presence, 5, 319-329. 
Verhagen, T., Feldberg, F., van den Hooff, B., Meents, S., \& Merikivi, J. (2011). Satisfaction with virtual worlds: An integrated model of experiential value. Information \& Management, 48, 201-207. doi: 10.1016/j.im.2011.02.004

Wang, C. X., Calandra, B., Hibbard, S. T., \& Mc Dowell Lefaiver, M. L. (2012). Learning effects of an experimental EFL program in Second Life. Education Tech Research Dev, 60, 943961. doi: 10.1007/s11423-012-9259-0

Warburton, S. (2009). MUVEs and Second Lives: Exploring education in virtual worlds. Proceedings of the KILT Conference, March 2008. London: King's College London.

Wehner, A. K., Gump, A. W., \& Downey, S. (2013). The effects of Second Life on the motivation of undergraduate students learning a foreign language. Computer Assisted Language Learning, 24(3), 277-289. doi: 10.1080/09588221.2010.551757 